\title{
Secondary Metabolites and Antioxidant Activity of Methanol Extract of Castanopsis costata Leaves
}

\author{
Maulana Y. Alkandahri ${ }^{1,2}$, Leo Nisriadi², Emil Salim ${ }^{3}$ \\ ${ }^{1}$ Faculty of Pharmacy, Universitas Padjadjaran, Jatinangor, West Java, Indonesia \\ ${ }^{2}$ Faculty of Pharmacy, Universitas Tjut Nyak Dhien, Medan, North Sumatra, Indonesia \\ ${ }^{3}$ Faculty of Pharmacy, Universitas Sumatera Utara, Meda, North Sumatra, Indonesia
}

\begin{abstract}
Castanopsis costata (C.costata) leaves were empirically used by people in North Sumatera, Indonesia, as an antioxidant dietary supplement. However, its pharmacological effect has not been scientifically explored. The purpose of this study was to identify the secondary metabolites and antioxidant activity of $C$. costata. The leaves were cold extracted with methanol. The secondary metabolites were determined using thin layer chromatography. Its antioxidant activity was investigated using 1,1-diphenyl-2-picrylhydrazyl (DPPH) method. The results showed that methanol extract of $C$. costata leaves consisted of alkaloids, flavonoids, glycosides, anthraquinone glycosides, tannins and triterpenoids. The methanol extract of $C$. costata leaves showed comparable antioxidant activity with vitamin $\mathrm{C} \mathrm{IC}_{50} 35.56 \mu \mathrm{g} /$ $\mathrm{ml}$ and $14.17 \mu \mathrm{g} / \mathrm{ml}$, respectively.
\end{abstract}

Keywords: Castanopsis costata leaves, methanol extract, antioxidant, DPPH, vitamin C.

\section{Introduction}

Free radicals reactive oxygen species are responsible for development of degenerative diseases such as atherosclerosis, coronary heart disease, stroke, cancer, and kidney failure. They are derived either from normal essential metabolic processes or from external sources such as exposure to x-rays, ozone, cigarette smoking, air pollutants, and industrial chemicals. ${ }^{1-3}$

Endogoneous antioxidants, such as catalase enzymes bound to $\mathrm{Fe}$, glutathione peroxidase, glutathione S-transferase binding to $\mathrm{Se}$, superoxide dismutase binding to $\mathrm{Cu}, \mathrm{Zn}$ and $\mathrm{Mn}$ are responsible to diminish free radical activities. However, an imbalance between free radical production and antioxidant can result in oxidative stress. Exogenous antioxidants are necessary to prevent harm caused by oxidative stress. ${ }^{4}$

Antioxidant compounds can be either from synthetic or natural compounds. Several studies showed that synthethic antioxidants such as butylated hydroxyanisole (BHA), butylated hydroxytoluene (BHT), propyl

Corresponding author: Maulana Y. Alkandahri, Faculty of Pharmacy, Universitas Padjadjaran, Jatinangor, West Java, Indonesia.Email: alkandahri@gmail.com

Received: 20 October 2016. Revised: 17 November 2016. Published: 1 December 2016. 
gallate (PG), and tert-butylhydroquinone (TBHQ) can cause several side effects. ${ }^{5}$ It encourages investigation to find new natural compounds as natural antioxidants which are safer for human health.

Natural compunds can be used as new sources of antioxidant. Major plant antioxidants were resulted from shikimic acid pathway and phenyl-propanoid metabolism. One of the plant that is empirically used as dietary antioxidant supplement is Castanopsis costata $(C$ costata) with the local name cepcepan plant. However, its pharmacological effect has not been scientifically explored yet. Thefore, this study was conducted to identify the secondary metabolites and antioxidant activity of $C$. Costata.

\section{Methods}

The materials used in this study were fresh C. Costata. leaves, 1,1-Diphenyl-2-picryl hydrazyl (DPPH), methanol, and destilled water. The chemicals used included alphanaphthol, ammonia, acetic acid anhydride, glacial acetic acid, concentrated hydrochloric acid, nitric acid, concentrated sulfuric acid, acetone, benzene, iron (III) chloride, bismuth (III) nitrate, iodine, isopropanol, potassium hydroxide, potassium iodide, whatmann paper no.1, chloroform, cuprisulfate, magnesium powder, mercury (II) chloride, sodium hydroxide, zinc powder, lead (II) acetate. Instrument used in this study was spectrophotometer ultraviolet-visible (Shimadzu).

\section{Plant determination}

Identification and determination of $C$. Costata. were conducted at Biology Department, Faculty of Mathematics and Natural Sciences, Universitas Padjadjaran.

\section{Extraction}

Cold extraction was obtained by immersing the sample in an methanol atroom temperature

Table 1. Phytochemical screening of $\boldsymbol{C}$. costata leaves methanol extract

\begin{tabular}{|c|c|c|c|c|}
\hline No & Secondary metabolite & Reagent & Observation & Result \\
\hline 1 & Alkaloid & $\begin{array}{l}\text { Dragendorff } \\
\text { Bouchardat } \\
\text { Mayer }\end{array}$ & $\begin{array}{l}\text { (+) Light brown } \\
(+) \text { Dark brown } \\
(+) \text { Muddy and white sediment }\end{array}$ & (+) Alkaloid \\
\hline 2 & Flavonoid & $\begin{array}{l}\mathrm{Zn}+\mathrm{HCl}(\mathrm{p}) \\
\mathrm{Mg}+\mathrm{HCl}(\mathrm{p})\end{array}$ & $(+)$ Red & $(+)$ Flavonoid \\
\hline 3 & a. Glycoside & $\begin{array}{l}\text { 1. Molish } \\
\text { 2. Fehling A+B }\end{array}$ & $\begin{array}{l}(+) \text { Purple ring } \\
(+) \text { Brown-red sediment }\end{array}$ & \\
\hline & b. Non Sugar & $\begin{array}{l}\text { Anhydride acetic } \\
\text { acid + sulfuric } \\
\text { acid }\end{array}$ & $(+)$ Brown-purple & \\
\hline 4 & Saponins & Hot water $+\mathrm{HCl}$ & (-) Bubble & (-) Saponins \\
\hline 5 & Glycoside Antraquinon & $\mathrm{NaOH}$ & (+) Purple-red in $\mathrm{NaOH}$ layer & $\begin{array}{l}(+) \text { Glycoside } \\
\text { Antraquinon }\end{array}$ \\
\hline 6 & Tannin & $\mathrm{FeCl}_{3} 1 \%$ & $(+)$ Yellow & $(+)$ Tannin \\
\hline 7. & Triterpenoid & $\begin{array}{l}\text { Anhydride acetic } \\
\text { acid }+ \text { sulfuric } \\
\text { acid }\end{array}$ & (+) Purple-brown & $(+)$ Triterpenoid \\
\hline
\end{tabular}


Table 2. DPPH absorbance of $C$. costata and vitamin $C$.

\begin{tabular}{cccccccc}
\hline \multirow{2}{*}{ No } & \multirow{2}{*}{ Extract } & \multirow{2}{*}{ DPPH } & \multicolumn{5}{c}{ Extract with various concentration $(\mu \mathrm{g} / \mathrm{ml})$} \\
\cline { 3 - 7 } & & 10 & 20 & 30 & 40 & 50 \\
\hline \multirow{3}{*}{1} & \multirow{2}{*}{ C. costata } & 0.69974 & 0.37671 & 0.35863 & 0.36457 & 0.34773 & 0.31025 \\
& & 0.69951 & 0.37697 & 0.35872 & 0.36416 & 0.34735 & 0.31472 \\
& 0.69927 & 0.37965 & 0.35879 & 0.36445 & 0.34769 & 0.31799 \\
\hline \multirow{3}{*}{2} & \multirow{2}{*}{ Vitamin C } & 0.69974 & 0.19834 & 0.18540 & 0.17831 & 0.15271 & 0.11756 \\
& & 0.69951 & 0.19832 & 0.18564 & 0.17743 & 0.15432 & 0.11773 \\
& 0.69927 & 0.19837 & 0.18553 & 0.17361 & 0.15925 & 0.11732 \\
\hline
\end{tabular}

for 5 x 24 hours. Separation of residue and filtrate were done every 1 x 24 hours. The filtrate was collected and concentrated using a rotary evaporator at $58^{\circ} \mathrm{C} .{ }^{6,7}$

Phytochemical screening

Phytochemical screening was performed using thin layer chromatography (TLC) and chemical reagents to prove the presence of bioactive compounds.

\section{Antioxidant activity}

Determination of antioxidant activity was performed using DPPH. ${ }^{8}$ DPPH $200 \mu \mathrm{g} / \mathrm{ml}$ stock solution was made by dissolving $20 \mathrm{mg}$ of DPPH to $100 \mathrm{ml}$ methanol. Sample solution was obtained by dissolving $25 \mathrm{mg}$ of viscous extract with $25 \mathrm{ml}$ of methanol. It was then diluted into $10,20,30,40$, and $50 \mu \mathrm{g} / \mathrm{ml}$. It was mixed until homogeneous and incubated at $37^{\circ} \mathrm{C}$ for 30 minutes. The antioxidant activity was carried out using spectrophotometry
UV-Vis at a wavelength of $515.50 \mathrm{~nm}$. The analysis was replicated three times. The inhibition concentration $\left(\mathrm{IC}_{50}\right)$ of $\mathrm{DPPH}$ was calculated using the following formula:

$\%$ Inhibition $=\frac{(\text { Blank Absorbance }- \text { Sample Absorbance })}{\text { Blank Absorbance }}$

\section{Results and Discussion}

Plant determination

Plant used in this study was determined as $C$. costata with the following identity:
Kingdom : Plantae
Division : Tracheophyta
Class : : : : :
Ordo : Fagales
Family : Fagaceae
Genus : Castanopsis
Species : Castanopsis costata.

The extraction and phytochemical screening

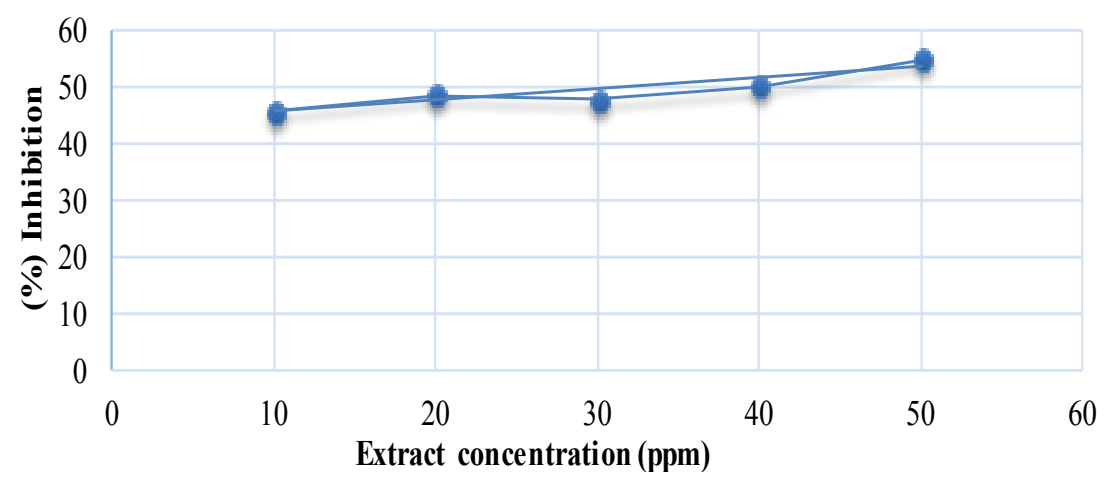

Figure 1. Inhibition activity of methanol extract of $C$. costata on DPPH 
Table 3. Antioxidant activity of $C$. costata and vitamin C

\begin{tabular}{llll}
\hline Sample & $\mathrm{IC}_{50}(\mathrm{ppm})$ & Value & \multicolumn{1}{c}{ Information on $\mathrm{IC}_{50}(\mathrm{ppm})$} \\
\hline Methanol extract & 35.56 & Very strong & $<50$ (very strong), 50-100 (strong), 100-150 \\
Vitamin C & 14.17 & Very srong & (average), 150-200 (weak) \\
\hline
\end{tabular}

The maceration resulted $4.0 \mathrm{~g}$ of viscous methanol extract of C. Costata. Phytochemical screening showed that this extract consisted of alkaloid, flavonoid, glycoside, antraquinon, tannin, and triterpenoid. The result is presented in the Table 1.

\section{Antioxidant activity}

Quantitative antioxidant activity determined by DPPH method was expressed as IC50, i.e., the concentration required to inhibit $50 \%$ of DPPH free radicals. ${ }^{9}$ Antioxidant activity of C. Costata methanol extract was performed at different concentrations. We found that the higher the concentration of the extract showed the higher of the percentage value of the inhibition. We observed a decrease in the absorbance of DPPH by the addition of combination of C. Costata and vitamin C. The higher concentration of the extract yielded the greater reduction of absorbance (Table 2, Figure 1).

We found that antioxidant activity of $C$. Costata leaves was comparable with that of vitamin $C$, which was in the category of very strong activity (Table 3 ). Polar substances such as polyphenol (flavonoid), cinnamic acid derivatives, coumarin, and tocopherol in C. Costata might contribute in its antioxidant activity. ${ }^{9,10}$

Polar substances are more easily dissolve in polar solvent such as methanol, ethanol, and water. Methanol has a polarity index of 5.1. Most polar compunds can be extracted using methanol and certain group of non polar compounds are fairly soluble in methanol.
Therefore, methanol is generally preferred for the extraction of bioactive compounds. Beside, it is relatively inexpensive and easily evaporated..$^{10-14}$

This is the first study investigating $C$. costata leaves antioxidant activity. This analysis could provide insight into the variations in the antioxidant profiles between different concentration of $C$. Costata. Further research might be necessary to examine the mechanism of its antioxidant activity.

\section{Conclusion}

The methanol extract of $C$. costata leaves had comparable antioxidant activity with vitamin $\mathrm{C}$, which showed the $\mathrm{IC}_{50}$ value of $35.56 \mathrm{ppm}$ and $14.17 \mathrm{ppm}$, respectively. Secondary metabolites of $C$. Costata leaves consisted of alkaloids, flavonoids, glycosides, anthraquinone glycosides, tannins and triterpenoids.

\section{References}

1. Pham-Huy LA, He H, Pham-Huy C. Free radicals, antioxidants in disease and gealth. International Journal of Biomedical Science. 2008;4(2):89-96.

2. Uttara B, Singh AV, Zamboni $\mathrm{P}$, et al. Oxidative stress and neurodegenerative diseases. Current Neuropharmacology. $\quad$ 2009;7(1):65-74. doi:10.2174/157015909787602823.

3. Lobo V, Patil A, Phatak A, Chandra N. Free radicals, antioxidants and functional foods: Impact on human health. Pharmacognosy Reviews. 2010;4(8):118126. 
4. Bouayed J, Bohn T. Exogenous antioxidants: double-edged swords in cellular redox state. Oxidative Medicine and Cellular Longevity. 2010;3(4):22823

5. Mut-Salud N, Álvarez PJ, Garrido JM, Carrasco E, Aránega A. Antioxidant intake and antitumor therapy: toward nutritional recommendations for optimal results. Oxidative Medicine and Cellular Longevity. 2016;2016:6719534.

6. Duthie G, Campbell F, Bestwick C, Stephen S, Russell W. Antioxidant Effectiveness of vegetable powders on the lipid and protein oxidative stability of cooked turkey: implications for health. Nutrients. 2013;5(4):1241-1252.

7. Aguayo-Rojas J, Mora-Rochín S, CuevasRodríguez EO, Serna-Saldívar SO. Phytochemicals and antioxidant capacity of tortillas obtained after lime-cooking extrusion process of whole pigmented mexican maize. Plant Foods and Human Nutrition. 2012;67:178-185.

8. Cote J., Caillet S., Doyon G. Bioactive compounds in cranberries and their biological properties. Critical Review on Food Science and Nutrition. 2010;50(7):666-679.

9. Landete JM. Dietary intake of natural antioxidants: Vitamins and polyphenols. Critical Review on Food Science and Nutrition. 2013;53:706-721.

10. Sasidharan S, Chen Y, Saravanan D, Sundram KM, Yoga Latha L. Extraction, Isolation and Characterization of Bioactive Compounds from Plants' Extracts. African Journal of Traditional, Complementary, and Alternative Medicines. 2011;8(1):1-10.

11. Kedare SB, Singh RP. Genesis and development of DPPH method of antioxidant assay. Journal of Food Science and Technology. 2011;48(4):412-422.

12. Sánchez JC, García RF, Cors MTM.
1,1-Diphenyl-2-picrylhydrazyl radical and superoxide anion scavenging activity of Rhizophora mangle (L.) bark. Pharmacognosy Research. 2010;2(5):279-284.

13. Ayala-Zavala JF, Perez-Carlon JJ, Esqueda M, Gonzalez-Aguilar GA, Leyva JM. Polar fractionation affects the antioxidant properties of methanolic extracts from species of genus Phellinus quel. International Journal of Medicinal Mushrooms. 2012;14:563-73.

14. Boeing JS, Barizão ÉO, Silva BC, Montanher PF, de Cinque Almeida $\mathrm{V}$. Evaluation of solvent effect on the extraction of phenolic compounds and antioxidant capacities from the berries: application of principal component analysis. Chemistry Central Journal. 2014;8:48. 